\title{
Molecular Biomarkers for Embryonic and Adult Neural Stem Cell and Neurogenesis
}

\author{
Juan Zhang ${ }^{1,2}$ and Jianwei Jiao ${ }^{1,3}$ \\ ${ }^{1}$ State Key Laboratory of Reproductive Biology, Institute of Zoology, Chinese Academy of Sciences, 1 Beichen West Road, \\ Chaoyang District, Beijing 100101, China \\ ${ }^{2}$ University of Chinese Academy of Sciences, No. 80 Zhongguancun East Road, Chaoyang District, Beijing 100190, China \\ ${ }^{3}$ Group of Neural Stem Cell and Neurogenesis, Institute of Zoology, Chinese Academy of Sciences, 1 Beichen West Road, \\ Chaoyang District, Beijing 100101, China
}

Correspondence should be addressed to Jianwei Jiao; jwjiao@ioz.ac.cn

Received 27 June 2014; Accepted 19 November 2014

Academic Editor: Giovanni Scapagnini

Copyright (C) 2015 J. Zhang and J. Jiao. This is an open access article distributed under the Creative Commons Attribution License, which permits unrestricted use, distribution, and reproduction in any medium, provided the original work is properly cited.

\begin{abstract}
The procedure of neurogenesis has made numerous achievements in the past decades, during which various molecular biomarkers have been emerging and have been broadly utilized for the investigation of embryonic and adult neural stem cell (NSC). Nevertheless, there is not a consistent and systematic illustration to depict the functional characteristics of the specific markers expressed in distinct cell types during the different stages of neurogenesis. Here we gathered and generalized a series of NSC biomarkers emerging during the procedures of embryonic and adult neural stem cell, which may be used to identify the subpopulation cells with distinguishing characters in different timeframes of neurogenesis. The identifications of cell patterns will provide applications to the detailed investigations of diverse developmental cell stages and the extents of cell differentiation, which will facilitate the tracing of cell time-course and fate determination of specific cell types and promote the further and literal discoveries of embryonic and adult neurogenesis. Meanwhile, via the utilization of comprehensive applications under the aiding of the systematic knowledge framework, researchers may broaden their insights into the derivation and establishment of novel technologies to analyze the more detailed process of embryogenesis and adult neurogenesis.
\end{abstract}

\section{Introduction}

Neural stem cells (NSCs) acting as a source of various cell types are a subpopulation of cells that can self-renewal and proliferate identical cells. They are multipotent to generate diversity neural lineages, encompassing neurons, astrocytes, and oligodendrocytes [1]. NSCs serving as an origin of neurons and glia throughout life were one of the milestone events of the past twenty-five years in the neuroscience research field [2], which is quite meaningful to the investigator majoring in the study of NSCs. NSCs with the plasticity to give rise to new neurons and glia play a crucial role in the embryogenesis and adult neurogenesis $[3,4]$.

The elemental discrimination between embryonic and adult neural stem cells is that the process of adult NSC is not orchestrated and massively paralleled progression as that in the embryonic developmental stages because such stages can occur at any time point [5].

NSCs, a headspring of progenitor cells in the central nervous system (CNS), are born with proliferation capacity of self-renewal and generation of both neurons and glia through a multistep process [6]. During the process of adult neurogenesis, NSCs in the germinal regions undergo numerous stages, including NSCs self-renewal, transient amplifying progenitors, neuroblasts, and terminally mature neurons, astrocytes, and oligodendrocytes $[2,5,7]$.

With the various technologies development, a quiet number of molecular biomarkers have been emerging like mushrooms after rain, which will favor the further research in the neuroscience field. However, there is not a systematic framework to illustrate the specific markers' detailed characters and functions. And our summary is tempting to provide 
such a commentary on these particular cell types for the best use of these powerful cells.

\section{Molecular Biomarkers during Embryogenesis}

During the embryogenesis, there are two crucial proliferative zones: ventricular zone (VZ) and subventricular zone (SVZ), which are the springheads of cortical neurons and glia cells [8]. NSCs locate at the VZ of the neural tube and produce all sorts of cell types necessary for the construction of the CNS [9]. The process of embryogenesis can be overviewed in Figure 1.

NSCs in the VZ divide symmetrically and asymmetrically to preserve the stem cell pool and generate progenitor cells, which subsequently migrate to SVZ and then perform the capability of proliferation or differentiation [10]. The SVZ may function as a peculiar zone that instructs the late-born neurons to establish the upper layers and terminally construct the neocortex [11].

The embryogenesis originates from the neural plate which is composed of neuroepithelial cells (NECs). Initially, the NECs divide symmetrically to amplify their own cohorts which are identified as the earliest form of embryonic NSCs $[12,13]$. And, after the formation of neural tube, NECs convert to radial glial cells, which locate the soma at the VZ and stretch the long radial fiber out of the neural tube internal surface to the outer (pial) surface [9]. On the one hand, the especial radial glial cells function as a scaffold to guide the migration of neuron. On the other hand, the characterized glial cells present the properties of embryonic NSCs. During this stage, radial glial cells accomplish a process of selfrenewal (a newborn radial glial cell) and generate one neuron (or a neuronal progenitor) from each asymmetrical division. Later, radial-glia cells differentiate into ependymal cells forming the neural tube of internal lining, and neurons migrate to the further layers along the radial filaments [14]. At the late stage of embryogenesis, radial glial cells will proliferate to produce oligodendrocytes and eventually astrocytes after the accomplishing of neuron formation. Closing to the date of birth, the radial glial cells change the characteristics to generate NSCs serving as a pool of adult neurogenesis and embryogenesis processes throughout life that can be found at Molecular Biomarkers during Adult Neurogenesis [12, 13].

Given the general frame of embryogenesis, we provide a subsection of this process to get a detailed understanding. The mouse cerebral neocortex can be factitiously partitioned into 6 layers horizontally, each of which contains a specific subpopulation of cells distinguished by singular or multiple markers identifying the characteristics functionally and molecularly [15]. Each layer is composed of pyramidal (glutamatergic excitatory projection) neurons and interneurons (GABAergic inhibitory interneurons). The newborn cortical neurons initially emerge at the mouse gestation of about embryonic day 10.5 (E10.5) and then form the preplate (PP), a cohort of cells located at the surface part (SP) of the cortical mantle.

And at E11.5, the cortical projection neurons present firstly in PP layer and migrate to establish the seminal cortical plate (CP), which whereafter progress to form L2L6 layers. Before the program of embryonic neurogenesis being launched, the neural progenitor cells (NPCs) in VZ divide symmetrically to amplify the neural progenitor pool. At around E11.5, NPCs get down to divide asymmetrically for self-renewal and to produce neurons which will subsequently migrate to mantle layers (MZ) along the scaffold acted by radial-glia cells (RGCs).

The projection neurons formed at the initial stage locate at the PP and build the nascent $\mathrm{CP}$, which will thenceforth convert into the neocortex L2-6. The increasing CP neurons subsequently crack the PP into SP and MZ. With the neurogenesis progressing, many projection neurons are created in sequence through the continuous asymmetric divisions of NPCs. Gathered together, neurons residing in SP are formed firstly, then those locating at deep layers, and at last those locating at the upper layers (L4, 3, and 2).

The formation of neocortex composed by neurons starts with deep layers; then the newborn neurons will migrate across the older ones to build upper layers. A part of daughter cells of NPCs transform into the IPCs, which will migrate away from $\mathrm{VZ}$ and go through symmetric divisions in SVZ, contributing to upper-layer neurons. At around E17.5, closing to the end of neurogenesis, the NPCs convert into gliogenesis, which produce cortical and subependymal zone (SEZ) astrocytes and form the layer of ependymal cells (EL) layer.

During the procedure of embryogenesis, different cell lineages generate different cell types in the different timecourses. And the specific cell types show exclusive cell surface proteins which can be applied to discriminate the particular cell type in specific stage from the NSCs pool. According to the characters above, various cell surface proteins can function as cell markers. And abundant biomarkers have been reported to identify the different cell lineages and different time-courses. Here, we listed the major ones for an illustration.

2.1. Emx2. Emx2, empty spiracles homolog 2, belongs to a homeobox-containing gene [18]. It is a transcription factor participating in the development of mouse cerebral cortex including proliferating neuroblasts originating from the neuroepithelium, VZ, and postmitotic Cajal-Retzius cells. Given the enrichment expression at the outset of corticogenesis, Emx2 is used broadly as a dorsal marker during the corticogenesis [19]. The results of Emx2 null embryos indicated that Emx2 as a transcription factor bears a critical part in regulating the neuroblast proliferation, migration, and differentiation. Moreover, Emx2 is also involved in the molding of the forebrain, the definition of cortical territories, and arealization during neocortical development [20].

2.2. Sox5. Sox 5 , sex determining region Y-box 5 (Sox5), is a transcription factor belonging to Sox family. It can be detected exclusively in postmitotic neurons of SP and in projection neurons of L6 at high level and in a cohort of L5 projection neurons. And the detectable phenotype persists from E14.5 to P7 (postnatal 7 days). Meanwhile, Sox 5 can also 


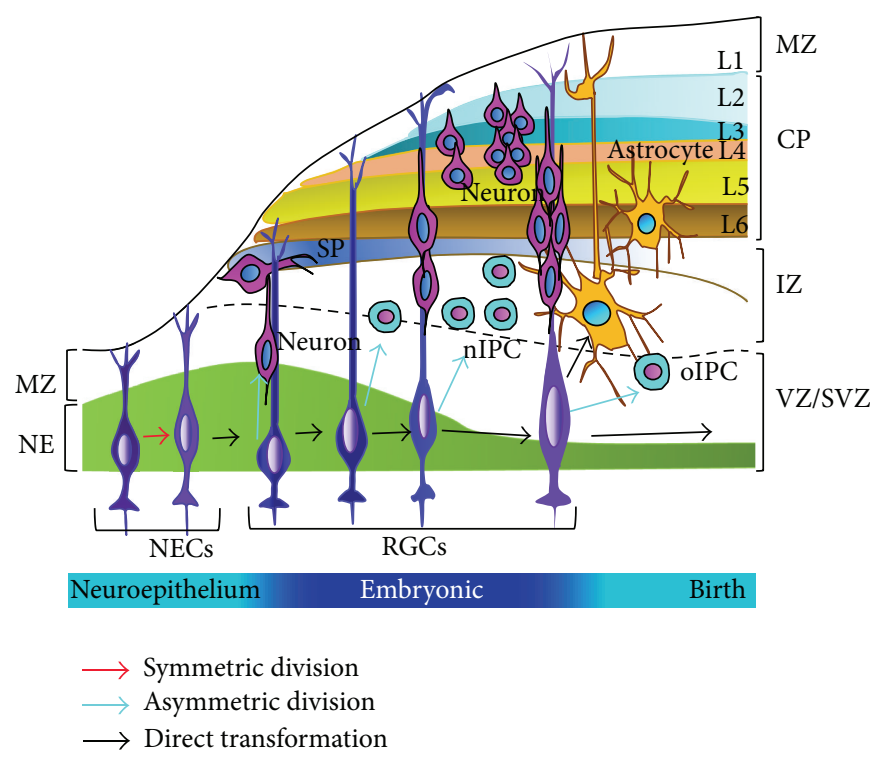

(a)

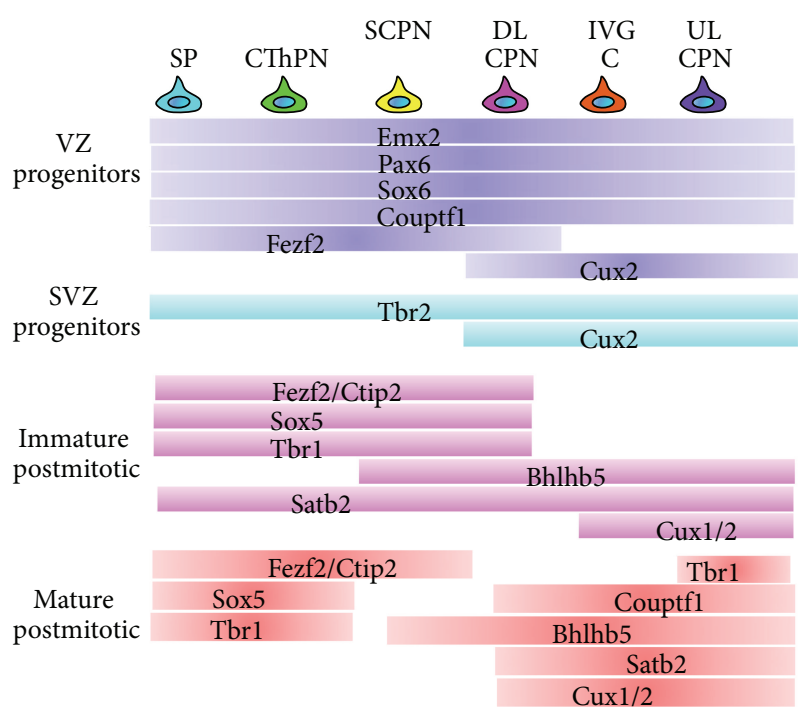

(b)

FIGURE 1: The schematic of embryogenesis and the specific markers expressed in specific time-line. (a) The process of embryogenesis. With the beginning of neuroepithelial cells, a series of cell types are produced, including radial glial cells, neurogenic intermediate progenitor cells, oligogenic intermediate progenitor cells, neurons, and astrocytes. (b) The specific markers indicate the specific cell types generated during the process of neurogenesis [16]. CP, cortical plate; DL, deep layer; GC, glial cells; IZ, intermediate zone; L1-6, layers 1-6; MZ, marginal zone; nIPC, neurogenic intermediate progenitor cell; NECs, neuroepithelium cells; oIPC, oligogenic intermediate progenitor cell; UL, upper layer; CPN, callosal projection neurons. RGCs, radial glial cells; SVZ, subventricular zone; SP, subplate; VZ, ventricular zone. CThPN, corticothalamic projection neurons; SCPN, subcerebral projection neurons.

be detected in a few of upper-layer neurons at low levels [2123].

Otherwise, investigation reported that Sox 5 is absent in the progenitor cells residing in VZ and SVZ [23]. In addition, Sox 5 is imperative for deep-layer neurons migration across the earlier-born neurons to fix on the more superficial layers. It might manipulate the migration of deep-layer neurons [24].

2.3. Bcl11b. Bcl11b (also called Ctip2), B cell leukemia/ lymphoma $11 \mathrm{~B}$, is a zinc finger transcription factor, which takes part in the development of L5 subcortical axon and is exclusively expressed in L5 [24, 25].

2.4. Tbr1. Tbrl, T-box brain factor 1 , is a transcription factor, which cooperates with Sox 5 to regulate early born neurons in multiple lines during the embryonic development. The deletion of Tbrl inmice indicated that it is necessary for numerous processes in cortical development, such as laminar location, molecular differentiation, and axonal expeditions [26-28]. The research has reported that Tbrl could be detected at E12.5 in the corticothalamic projection neurons which located in L6 and SP and in MZ Cajal-Retzius neurons, starting from E12.5 [26]. And, in progenitor cells that reside in VZ and SVZ, Tbrl is not detectable, which may imply the resemblance of Tbrl to Sox 5 in function. And when time-course progresses to the postnatal course, the layer specificity expression of Tbr1 is gradually downregulated but begins to present in several upper-layer neurons $[26,28,29]$. Additionally, Tbrl is also involved into the regulation of neuronal migration [27].
2.5. Fezf2. Fezf2 (also known as FEZL, ZFP312) belongs to FEZ family zinc finger 2, which also functions as a transcription factor. Fezf2 can be found in L5 cortical spinal (CS) neurons at a high level and plays a pivotal role in the CS tract development. Fezf2 is also found enriching in early progenitors of $\mathrm{VZ}$ and in their neuronal progenies which launch into the deep-layer of subcortex. Yet it disappeared in late progenitor cells and upper-layer neurons. Fezf2 is downregulated in L6 neurons during the late embryonic development $[27,28]$.

2.6. Satb2. Satb2, special AT-rich sequence-binding protein 2 (DNA-binding protein), is a matrix-attachment region interacting transcription factor, which can exclusively conjunct the nuclear matrix-attachment regions and plays a role in regulating the transcription and remodelling chromatin. It regulates the position of laminin and helps to identify the late-born neurons. It enriched the postmitotic neurons of corticocortical L2-L5, which begins to emerge in the E13.5 neurons when these neurons migrate into the IZ (intermediate zone) and will persist postnatally. Yet, in the subcortical projection neurons, it is not expressed [30,31]. Furthermore, SATB2, as an active transcriptional modulator, regulates a diversity of layer-specific markers for cortical projection neurons. The relative markers are listed as follows: Cdh10, cadherin 10; Cux2, cut-like homeobox 2; Rorb, RARrelated orphan receptor beta [31]. Scientists also reported that Satb2 also regulated the neuron dendritic arborization 
in upper layer (Zhang et al., 2011), referring to a wider role during neocortical development $[15,32]$.

2.7. Cux1/Cux2. Cux1/Cux2, cut-like homeobox 1/2, are upper layer-specific markers for neurons, which participate in the fundamental regulation of the late neuronal differentiation, spine formation, dendritic branching, and synaptogenesis in upper-layer (L2-3) neurons of the cortex $[33,34]$.

2.8. Pou3f2 and Pou3f3. Pou3f2 (POU class 3 homeobox 2, also called Brn-2) and Pou3f3 (POU class 3 homeobox 3, also called Brn-1) both are the members of the class III POU family transcription factors involved in neural differentiation [35]. POU3F2/POU3F3 is considered to be involved in upper-layer neuronal migration and identification, playing overlapping roles in the regulation of neocortical layers development $[36,37]$. Pou3f2 and Pou3f3 emerge in the L2-L5 projection neurons at E14.5 and continue presenting in the progenitor cells which amplify themselves and persist running through the migration and differentiation of postmigratory. Studies reported that the absence of Pou $3 \mathrm{f} 2 / 3$ led to reduction of upper layer-specific markers expression but did not affect the expression of markers for neurons in L6 and SP [36-38].

2.9. Pax6. Pax6, paired box 6, plays a pivotal role in the neuronal fate determination and NSCs proliferation. It participates in the neocortex positioning and upper-layer neurons generation via identifying the SVZ progenitor cells $[39,40]$. During the late mouse embryonic developmental stage of the cortical SVZ, Pax6 controls the neural progenitor cells proliferation by changing the Sox 2 expression [41].

2.10. Nr2f1. Nr2f1 (also known as Coup-tf1), nuclear receptor subfamily 2 , group F, member 1 , plays a crucial role in the neocortical regionalization. And the late-born neurons migration and the callosal projection neurons (CPNs) differentiation are modulated by Nr2f1 [42, 43].

2.11. Sox1. Soxl is expressed exclusively in the CNS and probably functions as the earliest marker for neural fate decision of embryonic stem cells. Furthermore, it marks the proliferating progenitors residing in the neural tube [44].

\section{Molecular Biomarkers during Adult Neurogenesis}

Adult neural stem cells are peculiar cell subpopulations with the character of structural plasticity [17]. In mammals, neurogenesis presents in two germinative regions: SVZ and SGZ throughout life [45]. Currently, various markers expressed at multistep strategies during the progressions of adult hippocampal neurogenesis have been discovered and developed [46, 47], which will be enumerated in the two major procedures of adult neurogenesis. The process of adult neurogenesis can be overviewed in Figure 2.

3.1. Developmental Process of Adult Neurogenesis in the Hippocampus. Radial-glia-like neural stem/precursor cells existing in the SGZ are usually regarded as relatively quiescent but can be activated by internal and external stimulus. They compose a pool of neuroblasts including transitamplifying and proliferative cells produced by symmetrically and asymmetrically dividing. Only a small bunch of cells in this pool can survive and differentiate into immature neurons. After the postdivision of 7-10 days, cells start to enter a neuronal fate $[17,48]$.

Radial-glia cells act dual-status during CNS development. On the one hand, they play as neural progenitor cells for neuronal generation and a scaffolding facilitating neuronal migration. And on the other hand, they act as a source of most neurons life-long in the CNS $[49,50]$.

Adult neurogenesis in the hippocampus germinates from progenitor cells and leads to the birth of granule cell neurons, which goes through approximately six distinct stages experiencing type- 1 cells, type- 2 a cells, type- 2 b cells, type- 3 cells and immature and mature neurons [5].

NSCs can be defined as a cohort that possesses both self-renewal and neurons/glia cells production from a unicell according to their potential capacities $[1,51]$. NSCs (defined as type- 1 cells) amplify intermediate progenitors (IPs, called as Type-2a cells) which keep expressing the stem/progenitor markers involving Sox2, a transcription factor [52]. And, at latish stage, neuronal determination starts to become obvious, overlapping with the transcription factors expression including Proxl, NeuroD1, and doublecortin (DCX) (type2b) [53]. These cells produce migratory neuroblasts (classified as Type-3 cells) which amplify but subsequently exit the cell cycle ahead of maturation into granule neurons. Presently, the procedure of adult neurogenesis can be separated into six developmental strategies factitiously according to the currently emerging investigations $[5,54]$.

Stage 1. Type-1 cells are a group of radial-glia-like neural stem cells with distinct morphology [55], which express astrocytic marker glial fibrillary acidic protein (GFAP) and nestin [56].

Stages 2-4. Type-1 cells assumedly divide asymmetrically generating daughter cells called type- 2 cells, which will form subsequently three consistent kinds of putative temporary augmenting progenitor cells, which can be characterized by the proliferation capacities, specific morphology, and their gradually increasing neuronal differentiation $[57,58]$. Type-2 cells are GFAP negative and are increasingly capable of proliferation $[55,59]$. They enter two subtypes: type-2a, nestinpositive and positive for doublecortin (DCX, an immature neuronal marker); type-2b, nestin and DCX-positive [60]. And type-3 cells, which display the polysialated form of neural cell adhesion molecule (PSA-NCAM), present DCXpositive and nestin-negative features [55, 61]. Meanwhile, the three cell types (type-2a, type-2b, and type- 3 cells) share some identical features during the three stages, which are classified into the neuronal lineage and labeled by 5 bromodeoxyuridine (BrdU) [5].

Stage 5. After the three stages above, cells are induced eventually to exodus from the cell cycle and enter an ephemeral postmitotic stage entering the early neuronal development 


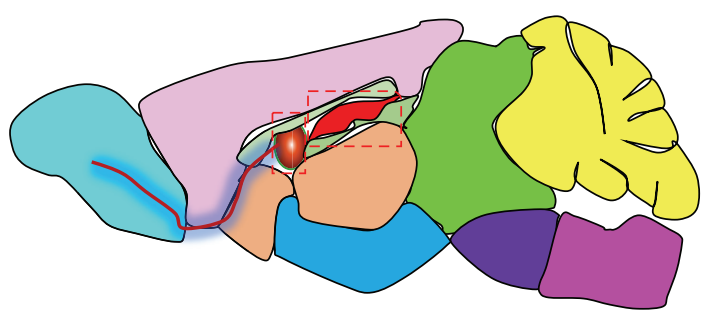

(a)

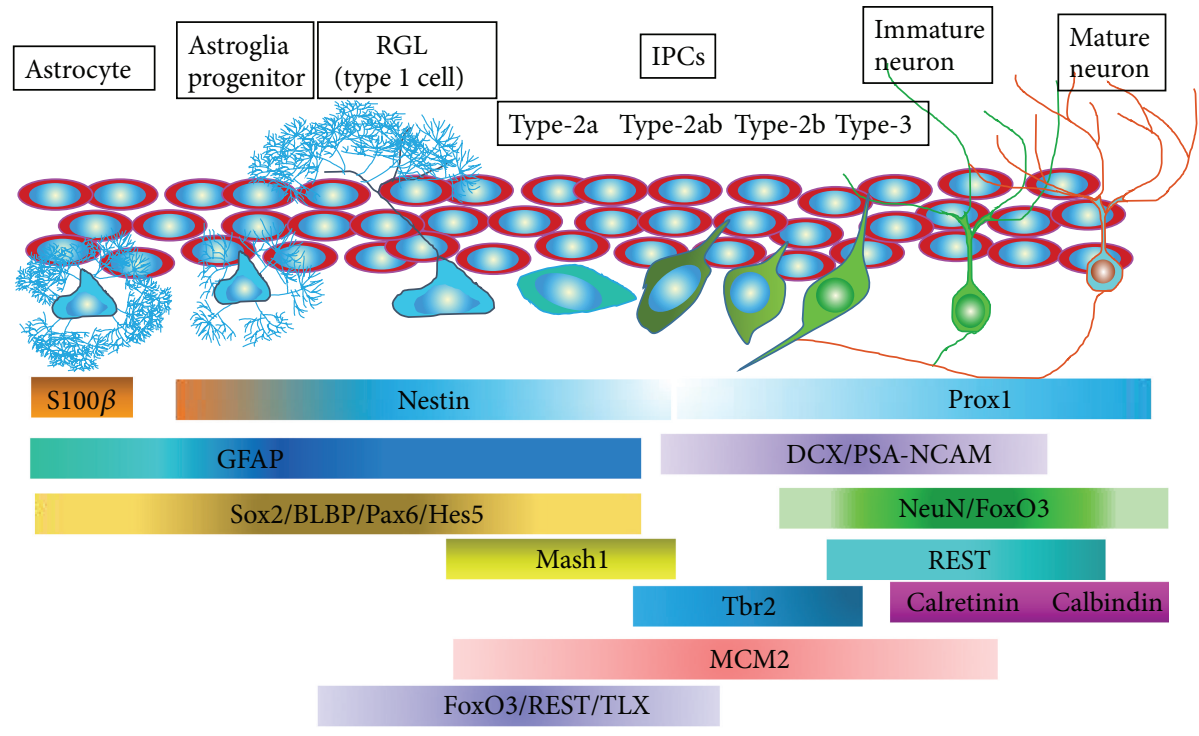

(b)

Figure 2: The schematic of adult neurogenesis and specific markers for specific cell types in different time-courses. (a) A model of the two major NSCs niches (labeled by the red panes) in the adult brain. (b) The process of adult neurogenesis originates from the active radial glial cells RGCs, (type-1 cells), generating intermediate progenitor cells (IPCs, type-2a, type-2ab, and type-2b cells), subsequently immature neurons, and finally mature neurons. The specific cell types emerging in the certain strategies are traced by various special markers [17]. GCL, granular cell layer; IPCs, intermediate progenitor cells; SGZ, subgranular zone.

and formatting immature neurons which can be marked by DCX, NeuN, and $\mathrm{Ca}^{2+}$-binding protein calretinin [62].

Stage 6. This is the stage of the ultimately mature new granule cells expressing calbindin. Thereabout 2-3 weeks after the postmitotic stage 5 , the new cells transform the calretininpositive cells to calbindin-positive cells [63].

During the process of neurogenesis, a number of diverse biomarkers can be utilized by immunohistochemical means labeling the specific cell types in diverse states. Following statements will delineate the developmental procedures of neurogenesis with the key identifications, accompanied with generally utilized stage-specific markers.

\subsection{Molecular Biomarkers in Hippocampal Neurogenesis.} With the progress of adult neurogenesis, a series of peculiar cell lineages emerge in turn. Here, we particularize the major biomarkers according to the following capabilities: proliferation, neurogenesis, and gliogenesis.

3.2.1. PCNA. PCNA, proliferating cell nuclear antigen, is important in both the repair and the replication of DNA. The expression of PCNA is increased during the $G_{1}$ and $S$ phases and decreased upon the cell converting into $G_{2}$ and $M$ phases. Nevertheless, this marker can also be detected in the early $\mathrm{G}_{0}$ phase, which is caused by the long half-life period of eight to twenty hours [64]. Therefore, it refers to the fact that PCNA is expressed in the whole process of cell cycle. As a proliferation marker, it is usually applied to mark a subgroup of actively dividing cells, which is an indicator of proliferating NSCs (PCNA-positive cells) in SVZ, SGZ, tracing for the elusive adult NSCs $[64,65]$.

3.2.2. Ki67. Ki67, also known as MKI67, is a nuclear protein, which can be used as a marker for dividing cells. It can be found in all time-courses of cell cycle but $G_{0}$ and early $G_{1}$ phases and the same to quiescent cells [64]. According to the above investigation, both PCNA and Ki-67 can be used to label dividing cells, but PCNA is broader than Ki67 [66].

3.2.3. $\mathrm{PH}$ 3. $\mathrm{PH} 3$, phosphohistone $\mathrm{H} 3$, is expressed at the late stage of $G_{2}$ phase and the entire course of $M$ phase during cell division [67]. Given the property of $\mathrm{PH} 3$, it is usually applied to seek the cell subgroups in proliferating and mitotic states [68]. 
3.2.4. BrdU. BrdU ( $5^{\prime}$-bromo- $2^{\prime}$-deoxyuridine), thymidine analog, is usually used to label cells being in the cell cycle of $S$ phase in both embryonic and adult dividing cells. However, BrdU uniquely labeling, without additional markers, is only a prevalent symbolization for neurogenesis. BrdU-positive cells may indicate a subtype of progenitors for new neurons but not progenitors for neuronal cells [69-71].

3.2.5. MCM2. MCM2, minichromosome maintenance protein 2, is associated with the DNA replication. It is expressed at the early stage of $G_{1}$ phase and is sustained throughout cell cycle. Besides, it can be detected in proliferating cells without DNA synthesis too. Its expression level is thus higher than Ki67 which is the short-lived cell proliferation marker [72]. Furthermore, MCM2 has been confirmed to unfold a better tool for the labeling of cell proliferation than Ki67 and has been identified as a more useful marker in adult neurogenesis [73].

3.2.6. GFAP. GFAP, glial fibrillary acidic protein, is an intermediate filament (IF) protein which works as a holder of astrocyte mechanical strength. It is a well-known marker for astrocytes [74]. It has been reported that cells with astrocytic property can serve as an origination of new neurons during adult neurogenesis [75]. Rising proof suggests that GFAPpositive progenitor cells can generate specific cell types of neurons during neurogenesis [76]. Radial astrocytes stretching across the granule cell layer are assumed as potential DG NSCs [55].

3.2.7. BLBP. BLBP, brain lipid binding protein (BLBP), also called B-FABP or FABP7, is subjected to a member of fatty acid-binding proteins (FABPs) family, which are cytoplasmic proteins undertaking fatty acid intake, transportation, and targeting [77]. BLBP extensively serves as a radial-glia cell marker in both embryonic and adult brain developments and is expressed in the astrocyte lineage [78, 79]. It also presents in type- 1 cells and a handful of type- 2 cells in SGZ [80, 81]. The advent of BLBP in activated astrocytes is related to the expression of oligodendrocyte progenitor cells $[50,82]$.

3.2.8. Sox2. Sox2, known as SRY (sex determining region Y)box 2, is a member of Sox family of transcription factors. It encodes a highly conserved DNA-binding motif identified as HMG (high-mobility group) box, playing vital roles in distinct stages of mammalian development. Sox2, presenting a high expression in embryonic stem cells and adult NSCs during development [83-85], is a frequency marker for NSCs and is thought to be critical for NSCs proliferation and differentiation. Sox2-positive cells proliferate a subpopulation of undifferentiated, dividing cells in the subgranular zone (SGZ) of adult dentate gyrus. They are capable of generating differentiated cells and identical Sox2-positive cells, indicating their multipotent properties and capacities of self-renewal in the adult brain [86].

On the other hand, Soxl is also expressed in adult neural progenitor cells and multipotent neural stem cells in vitro [87].
3.2.9. PSA-NCAM. PSA-NCAM, polysialylated neural cell adhesion molecule, is highly expressed in neural progenitor cells or mostly glial progenitor cells during brain development [88]. As for the adult brain, PSA-NCAM-positive cells can be focused on the granule cells that are newly generated or in the developing process in the adult brain $[89,90]$. It has also been identified as a migrating neuroblasts marker that became neurons in the olfactory bulb (OB) in the SVZ in vivo [91]. Additionally, most of PSA-NCAM-positive cells is also NeuroD-positive, doublecortin-positive, NeuN-positive but GFAP-negative. Therefore, PSA-NCAM can be considered as a marker that arrives at the late strategy of adult neurogenesis $[89,90]$.

3.2.10. NeuroD. NeuroD (neurogenic differentiation) is a transcription factor belonging to the family of basic helixloop-helix protein. It is presented in later strategies of neuronal progression and is classified as a differentiation indicator for neurogenesis, which may serve as a neuronal determination gene. It can also serve as a specific marker of adult cells in SGZ and inner granule layer [92, 93]. It is basilic for the proliferation of neurons in the adult brain [94]. Meanwhile, the expression of NeuroD can also be detected in PSA-NCAM-positive cells and it is colabeled with about $50 \%$ of Pax6-positive cells [95].

3.2.11. Pax6. PAX6, paired box 6, is a member of the paired box (Pax) family. As a conserved transcription factor with different DNA-binding domains (PD, a paired domain, and HD, a paired-type homeodomain), Pax6 is intensely expressed in the cells originating from the embryonic neural development and adult neurogenic niches [96]. It is multifunctional in regulating NSCs proliferation and differentiation by the modulation of various downstream molecules expression. It possesses the capacity of fate specification which sustains the survival of the distinct neuronal subtypes in the adulthood [97]. And its expression in progenitor cells is arrested at the early postnatal periods and is maintained only in adult neural progenitor cells in the restrict regions of SGZ and SVZ [98].

As a transcription factor, Pax6 emerges in embryonic progenitor cells and participates in the cell proliferation and the determination of neuronal fate as a pivotal regulator [99]. Nacher's investigation showed that Pax6 also turns up in the resident cells of adult SVZ and SGZ [95]. In the SGZ, Pax6 can be found in early progenitor cells with radial-glia-like appearance and GFAP/nestin-positive [93, 96]. Yet, there is a small bunch of cells exhibiting both Pax6 and PSA-NCAM or DCX or even NeuroD [100-102]. Pax6, collaborating with Dlx2, is required to specify and maintain neuronal subtype peculiarity in the adult and developing brain $[103,104]$. Taking together, Pax6 might be used to classify the newly born cells from the differentiation state in SGZ.

3.2.12. FoxO3. FoxO3 (forkhead box O3) is a transcription factor belonging to the $\mathrm{O}$ subclass of the forkhead family which are identified by an evident fork head DNA-binding domain. FoxO factors can lure a series of cellular responses, involving the arrest of cell cycle, cell differentiation, apoptosis, and the opposition to oxidative stress [105]. FoxO3 protein 
can be detected in adult NSCs/progenitor cells in the adult mouse brain [106]. And FoxO3 probably acts as an activator of apoptosis through upregulating the genes necessary for cell death and downregulating antiapoptotic proteins [107] and as a key player in Notch signaling pathway which is essential for sustaining the adult NSCs quiescent state [108]. The gene expression profile of FoxO3 in NSCs indicates that FoxO3 maintains the homeostasis of mouse NSC pool by provoking the genes that sustains quiescence, prohibits premature differentiation, and regulates oxygen metabolism [106].

3.2.13. Nestin. Nestin, neuroepithelial stem cell protein, is a sort of intermediate filament protein involved in classes VI and IV, which is expressed transiently in adult NSCs, immature neural progenitor cells, and vanishes upon the cells converting into differentiation [109]. It has been frequently utilized as a marker of NSCs both in embryo and in adult brain [110]. Park's data also suggests that nestin is basilic for the survival and self-renewal of NSCs [111].

In the adult mouse brain, nestin-positive cells can be observed extensively in restricted regions, where they might serve as a niche of stem/progenitor cells with the capacity of proliferation and differentiation [112]. During embryogenesis, most nestin-positive cells in early developmental stage indicate a cohort of stem/progenitor cells encompassed in active proliferation [113]. Upon these cells halting to divide and engaging into differentiation, nestin expression will be downregulated [113]. In the adult mouse brain, nestin-positive cells can be observed extensively in restricted regions, where they might serve as a niche of stem/progenitor cells with the capacity of proliferation and differentiation [112].

3.2.14. TLX. TLX, an orphan nuclear receptor (also called NR2E1), is encoded by the tailless (TLX) gene. It can be found in both neural stem/progenitor cells (quiescent NSCs) and transit-amplifying neural progenitors (active NSCs) in the SVZ (subventricular zone) and SGZ (subgranular zone) of adult mouse brain [114-116]. It is important in regulating NSCs self-renewal and proliferation during embryonic development and adulthood via a cell-autonomous mode [117]. And the adult neural stem cell pool consists of TLX-positive cells [116].

TLX is uniquely expressed by astrocyte-like B cells of SVZ. And the deletion of TLX gene may result in an absolute loss of SVZ neurogenesis and the deprivation of NSC property of GFAP-positive cells [115]. Further analysis of TLX indicates an essential role during the identified transition from radial glial cells to astrocyte-like B cells, which suggests that TLX should play as a crucial role in the process of the adult NSCs generation and maintenance in the SVZ [114].

3.2.15. $b H L H$. The bHLH is a basic helix-loop-helix protein transcription factor family, which regulates vertebrate neurogenesis, showing the capacity of transforming nonneuronal fate to neuronal fate when it is expressed ectopically [118].
3.2.16. Hes5. Hes5 is a member of Hes genes (mammalian homologues of Drosophila hairy and Enhancer of split genes) which can encode a series of basic helix-loop-helix (bHLH) transcriptional repressors. There are three conserved domains (bHLH, Orange, and WRPW domains) involved in Hes5 factor, through which Hes5 factor can set up transcriptional activities [9]. Studies have shown that, during embryogenesis, cells expressing Hes5 are maintained as neural stem cells. Hes5 habituates specifically in the SGZ, being in line with property of progenitor cells in the neurogenic niche $[119,120]$. And the Hes5::GFP can mark more restricted and undifferentiated cohorts than Sox2 and BLBP [120].

3.2.17. Mash1. Mash1, mammalian achaete-scute homolog (also called Ascl1), is a bHLH transcription factor, which is essential for embryonic neural differentiation [121]. It is dynamically expressed not only in the intermediate progenitor cells (type C cells) but also in a subpopulation of NSCs potential for long-term neurogenesis in SVZ and SGZ of adult brain $[115,122]$.

3.2.18. REST. REST, RE1-silencing transcription factor (also known as NRSF), is the GLI-Kruppel class C2H2 zinc finger protein expressed in various neuronal genes [123]. It can silence the gene expression via recruiting $\mathrm{mSin} 3 \mathrm{~A} / \mathrm{B}$ and CoREST $[124,125]$. It can be found in nonneural cells and embryonic stem cells at high levels but declines when embryonic stem cells transfer to NSCs and cortical progenitor cells [125]. Conversely, REST highlights obvious levels in granular and pyramidal neurons in adult brain [126]. There is a putative implication that REST shows distinct functions when it arrives at embryonic and adult timelines. The deletion of REST may result in the functional depletion of adult NSC pool, which implies the crucial role of REST in sustaining the quiescent state of adult NSCs [127].

3.2.19. DCX. DCX, doublecortin, a protein facilitating microtubule polymerization, is expressed in migrating neuroblasts and immature neurons, which can be classified as a marker for adult neurogenesis in SGZ. However, not all newly born neurons express DCX. It can be found in newly generated hippocampal, striatal, and olfactory neurons, but not in newly generated neurons in the neocortex [128]. In a word, DCX can be utilized to label the postmitotic neuronal progenitor cells and early immature neurons [60]. And a tiny episode of overlap can be seen between the DCX-positive and nestin-positive cells [129].

3.2.20. Vimentin. Vimentin and GFAP are the two main intermediate filament proteins which imply the property of glial cells. And vimentin is mainly exhibited in the radial-glia and immature astrocytes of the early brain development and vanishes at the terminal of gestation. Simultaneously, GFAP presents in the astroglia cells instead of vimentin. However, Seri's research also suggests that vimentin is expressed in both radial-glia and horizontal cells in SGZ $[68,130]$. 
3.2.21. S100 $\beta$. S100 $\beta$, also called calcium binding protein $\beta$, is a member of the S100 family, which is anchored at the cytoplasm and nucleus and participates in the procedure of cell cycle and differentiation. It can be detected in a subgroup of specific postmitotic astrocytes [131]. The expression of S100 $\beta$ discriminates a cohort of cells losing their NSCs potential from the GFAP-positive cells and indicates a more mature stage [132]. Given the above messages, we can conclude that $\mathrm{GFAP}^{+}$and nestin ${ }^{+}$progenitor cells are negative for $\mathrm{S} 100 \beta$ [55]. It has been reported that $S 100 \beta$ could be reflected by immunofluorescent staining in horizontal zone but not radial astrocytes in SGZ [133].

3.2.22. GLAST and GLT1. GLAST (also known as EAAT1) is astrocyte-specific glutamate transporter and GLT1 (also known as EAAT2) is glutamate transporter; both are defined as markers of glial group [134]. GLAST has been found presenting in most of S100 $\beta$-positive cells in SGZ [135]. It initially presents at mouse embryonic days 13/14 (E13/14) and keeps on throughout adulthood [136]. Nevertheless, the results derived from the adult NSCs culture in vitro showed that both GLAST and GLT could be detected in neuronal subgroups. Otherwise, investigations also unfolded that nestin-positive and Sox2-positive NSCs could be found expressing GLAST and GFAP $[137,138]$.

3.2.23. Tbr2. Tbr2, T-box brain gene 2, is a member of the mammalian brain-specific T-box gene family, which was expressed in a couple of regions in the developing brain. Yet, it is absent in most regions of adult brain but hippocampus and OB [139]. Increasing proofs have shown that Tbr2 is involved in adult neurogenesis in SGZ. It is present in a small bunch of Sox 2 and Pax6-positive cells but absent in the S100 $\beta$-positive cells. It overlaps with NeuroD-positive cells, as well as DCX ${ }^{+}$and PSA-NCAM ${ }^{+}$cells. And Tbr2 gradually disappeared when the cells are predestined to convert into neurons and exit mitotic cycle. Thus, it is not detectable either in calretinin/calbindin-positive immature neurons or in NeuN-positive mature cells. Together, we can conclude that Tbr2 is restrictedly expressed in type- 2 and a handful of type-3 progenitor cells $[68,93,140]$.

3.2.24. NeuroD. NeuroD, the basic helix-loop-helix protein, is a transcription factor, which has been parted into the group of markers for differentiated cells during neurogenesis in the SGZ [92]. It can be observed in inner granule cell layer and in a half of Pax6 and NeuroD-positive cells as well as PSA-NCAM-positive ones [93, 95, 133]. Gathered together, NeuroD can be defined as a marker for the early neuronal lineage and for the identification of mitotic neuronal cells [68].

3.2.25. Tuj1. Tuj1, neuron-specific class III $\beta$-tubulin, can be detected in immature neurons starting up at mouse early embryonic 8.5 day and persisting throughout the adulthood. The Tuj1-positive cells can be colabeled with DCX-positive and PSA-NCA-positive cells [141, 142]. Furthermore, it has been reported that Tuj1 can also be detected in basket cells in SGZ [133].

3.2.26. Proxl. Proxl, prosperorelated homeobox gene 1, is necessary for the preservation of IPCs (intermediate progenitor cells) and is needed to promote granule cells to maturate during the procedure of adult neurogenesis [143]. It is absent in nestin ${ }^{+}$or Sox $2^{+}$cells but can be found in $\mathrm{DCX}^{+}$cells and calretinin ${ }^{+}$cells in the adult granule cells [144]. It can be applied to trace the neuronal lineage and mature neurons in the SGZ $[53,144]$.

3.2.27. CNPase. CNPase, $2^{\prime}, 3^{\prime}$-cyclic-nucleotide $3^{\prime}$-phosphodiesterase, presents specifically in oligodendrocytes in SVZ and SGZ, whose morphology reflected by the immunostaining refers to the beginning of oligodendrocyte differentiation. Furthermore, it is considered to play a leading role in the formation of myelination $[145,146]$.

3.3. Molecular Biomarkers in Adult SVZ. Subventricular zone (SVZ) is the other NSCs pool of the two restricted regions. The SVZ mainly consists of four main cell types: SVZ astrocytes/NSCs (type B cells), intermediate progenitor cells (type C cells), neuroblasts (type A cells), and ependymal cells $[75,147]$. The adult SVZ functions as a neurogenesis pool through a surprising resemblance to the embryonic SVZ [148]. Experiencing the embryogenesis, the neonatal radialglia (RG) cells persist to produce neurons and oligodendrocytes which originate from the intermediate progenitor cells (IPCs). One group of these cells transforms into ependymal cells, and most of the left cells convert into astrocytes (called type B cells) locating at adult SVZ, which continue to serve as NSCs throughout the adulthood. B cells preserve the epithelial formation which fix the apical into the ventricle zone and terminate the basal layer in blood vessels. Type B cells express markers tracing for astroglia, such as GFAP, glial fibrillary acidic protein; GLAST, astrocyte-specific glutamate transporter; BLBP, brain-lipid-binding protein; and nestin $[148,149]$.

And the slowly dividing astrocytes (B cells) continue to produce precursor $\mathrm{C}$ cells (intermediate progenitor cells), and $\mathrm{C}$ cells can produce the specific lineage A cells (neuroblasts) which will migrate along the RMS (rostral migratory stream) to the OB (olfactory bulb) where they finish their destined mission and convert into granule neurons [150].

GFAP specifically marks the NSCs and astrocytes residing in the SVZ but does not mark the subgroup of TAPs (transient amplifying progenitor cells) [78]. Meanwhile, Ki67, MCM2 (minichromosome maintenance 2), and PH3 (phosphohistone $\mathrm{H} 3$ ) can be used to mark the nuclei of proliferating cells, which make NSC nuclei visual in single one.

Sox 2 marks the active astrocytes (NSCs) and neural progenitors (TAPs) of SVZ [75, 84]. PSA-NCAM marks the neuroblasts. NG2 and Mash1 exclusively mark the TAPs and a subgroup of migrating neuroblasts [151]. S100 $\beta$ marks the astrocytes and ependymal cells [152]. CD24 marks the migrating immature neurons and ependymal cells. CD31 (PECAM-1) marks the vascular endothelial cells [153]. In the 
SVZ, cells that transform into another morphology through a series of time-courses can be marked by Tuj1 for neurons, GFAP for astrocytes, and O4/CNPase for oligodendrocytes (O4 and CNPase) [154].

Besides the markers mentioned above, a number of biomarkers reported in abundant investigations are remaining. Here, we enumerate some of them that were not illustrated in this review.

Astrocytes Markers. These include Aldh1L1, aldehyde dehydrogenase family 1 member L1; Bysl, bystin; GjA1, connexin 43; Glul, glutamine synthetase; PygB, glycogen phosphorylase; Slc1A2 GLT-1, excitatory amino acid transporter 2; Slc1A3, Glast-1, excitatory amino acid transporter 1.

Radial-Glia Markers. These include Aqp4, aquaporin-4; Slc1A2 GLT-1, excitatory amino acid transporter 2.

Oligodendrocyte Markers. These include Olig2, oligodendrocyte transcription factor; Car2, carbonic anhydrase 2; NFIA, nuclear factor $1 \mathrm{~A}$-type; NFIB, nuclear factor 1 B-type; NFIX, nuclear factor 1 X-type; NSCs: NFIA, nuclear factor 1 A-type; NFIB, nuclear factor 1 B-type; Slc1A2 GLT-1, excitatory amino acid transporter 2 .

\section{Concluding Remarks}

Given so abundant investigations and reviews by so many prominent scientists, we can now sketch the outline of various biomarker functional characteristics and latent application in multiple aspects. Gathering all of the formulations above, we catch a sight of many milestones established in the development of neurogenesis as well as obstacles being unfathomed.

Neural stem cells (NSCs) are the fundamental source of all cell types in the CNS. To grasp the nature of niche components in the mouse brain, we need to understand the major characteristics and functions of each element in the niche, to comprehend what role each cellular member plays in the procedure of NSCs maintenance, proliferation, and differentiation. However, it is difficult, using a single marker, to identify a single cell lineage exclusively. And thus it is necessary to apply multiple markers to the analysis of one peculiar cell type. Recently, numerous methods and technologies have been emerging to classify and identify the specific cell types during the neurogenesis of both embryonic and adult brains. Nevertheless, each approach possesses shining points and flaws. We need more concerns to consummate them.

\section{Conflict of Interests}

The authors declare that there is no actual or potential conflict of interests to this work, including any financial, personal, or other relationships with relevant people or organizations.

\section{Acknowledgments}

This work was supported by the Ministry of Science and Technology of China (2014CB964903) and Strategic Priority
Research Program (XDA01020301). The work submitted has not been published previously, and it is not under consideration for publication elsewhere.

\section{References}

[1] F. H. Gage, "Mammalian neural stem cells," Science, vol. 287, no. 5457, pp. 1433-1438, 2000.

[2] F. H. Gage and S. Temple, "Neural stem cells: generating and regenerating the brain," Neuron, vol. 80, no. 3, pp. 588-601, 2013.

[3] P. Taupin, "Adult neurogenesis and neuroplasticity," Restorative Neurology and Neuroscience, vol. 24, no. 1, pp. 9-15, 2006.

[4] G.-L. Ming and H. Song, "Adult neurogenesis in the mammalian central nervous system," Annual Review of Neuroscience, vol. 28, pp. 223-250, 2005.

[5] G. Kempermann, S. Jessberger, B. Steiner, and G. Kronenberg, "Milestones of neuronal development in the adult hippocampus," Trends in Neurosciences, vol. 27, no. 8, pp. 447-452, 2004.

[6] I. Imayoshi, M. Sakamoto, T. Ohtsuka, and R. Kageyama, "Continuous neurogenesis in the adult brain," Development Growth \& Differentiation, vol. 51, no. 3, pp. 379-386, 2009.

[7] L. de Filippis, G. Lamorte, E. Y. Snyder, A. Malgaroli, and A. L. Vescovi, "A novel, immortal, and multipotent human neural stem cell line generating functional neurons and oligodendrocytes," Stem Cells, vol. 25, no. 9, pp. 2312-2321, 2007.

[8] L. Pevny and M. S. Rao, “The stem-cell menagerie," Trends in Neurosciences, vol. 26, no. 7, pp. 351-359, 2003.

[9] R. Kageyama, J. Hatakeyama, and T. Ohtsuka, "Roles of Hes bHLH factors in neural development," in Transcription Factors in the Nervous System: Development, Brain Function, and Diseases, pp. 3-22, Wiley, 2006.

[10] F. Guillemot, "Cellular and molecular control of neurogenesis in the mammalian telencephalon," Current Opinion in Cell Biology, vol. 17, no. 6, pp. 639-647, 2005.

[11] K. Campbell, "Cortical neuron specification: it has its time and place," Neuron, vol. 46, no. 3, pp. 373-376, 2005.

[12] A. Alvarez-Buylla, J. M. García-Verdugo, and A. D. Tramontin, "A unified hypothesis on the lineage of neural stem cells," Nature Reviews Neuroscience, vol. 2, no. 4, pp. 287-293, 2001.

[13] S. Fujita, "The discovery of the matrix cell, the identification of the multipotent neural stem cell and the development of the central nervous system," Cell Structure and Function, vol. 28, no. 4, pp. 205-228, 2003.

[14] D. Gleason, J. H. Fallon, M. Guerra, J.-C. Liu, and P. J. Bryant, "Ependymal stem cells divide asymmetrically and transfer progeny into the subventricular zone when activated by injury," Neuroscience, vol. 156, no. 1, pp. 81-88, 2008.

[15] K. Y. Kwan, N. Šestan, and E. S. Anton, "Transcriptional coregulation of neuronal migration and laminar identity in the neocortex," Development, vol. 139, no. 9, pp. 1535-1546, 2012.

[16] M. B. Woodworth, L. Custo Greig, A. R. Kriegstein, and J. D. MacKlis, "SnapShot: cortical development," Cell, vol. 151, no. 4, pp. 918-e1, 2012.

[17] K. C. Vadodaria and F. H. Gage, "SnapShot: adult hippocampal neurogenesis," Cell, vol. 156, no. 5, pp. 1114-1114.e1, 2014.

[18] A. Mallamaci, R. Iannone, P. Briata et al., "EMX2 protein in the developing mouse brain and olfactory area," Mechanisms of Development, vol. 77, no. 2, pp. 165-172, 1998.

[19] C. Cecchi, A. Mallamaci, and E. Boncinelli, "Mouse forebrain development. The role of Emx2 homeobox gene," Comptes 
Rendus de l'Académie des Sciences, vol. 322, no. 10, pp. 837-842, 1999.

[20] C. Cecchi, "Emx2: a gene responsible for cortical development, regionalization and area specification," Gene, vol. 291, no. 1-2, pp. 1-9, 2002.

[21] K. Y. Kwan, M. M. S. Lam, M. B. Johnson et al., "Speciesdependent posttranscriptional regulation of NOS1 by FMRP in the developing cerebral cortex," Cell, vol. 149, no. 4, pp. 899-911, 2012.

[22] T. Lai, D. Jabaudon, B. J. Molyneaux et al., "SOX5 controls the sequential generation of distinct corticofugal neuron subtypes," Neuron, vol. 57, no. 2, pp. 232-247, 2008.

[23] K. Y. Kwan, M. M. S. Lam, Ž. Krsnik, Y. I. Kawasawa, V. Lefebvre, and N. Šestan, "SOX5 postmitotically regulates migration, postmigratory differentiation, and projections of subplate and deep-layer neocortical neurons," Proceedings of the National Academy of Sciences of the United States of America, vol. 105, no. 41, pp. 16021-16026, 2008.

[24] P. Arlotta, B. J. Molyneaux, J. Chen, J. Inoue, R. Kominami, and J. D. MacKlis, "Neuronal subtype-specific genes that control corticospinal motor neuron development in vivo," Neuron, vol. 45, no. 2, pp. 207-221, 2005.

[25] R. Simon, H. Brylka, H. Schwegler et al., "A dual function of Bcl11b/Ctip2 in hippocampal neurogenesis," The EMBO Journal, vol. 31, no. 13, pp. 2922-2936, 2012.

[26] R. F. Hevner, L. Shi, N. Justice et al., "Tbrl regulates differentiation of the preplate and layer 6," Neuron, vol. 29, no. 2, pp. 353-366, 2001.

[27] W. Han, K. Y. Kwan, S. Shim et al., “TBR1 directly represses Fezf2to control the laminar origin and development of the corticospinal tract," Proceedings of the National Academy of Sciences of the United States of America, vol. 108, no. 7, pp. 30413046, 2011.

[28] W. L. McKenna, J. Betancourt, K. A. Larkin et al., “Tbrl and Fezf2 regulate alternate corticofugal neuronal identities during neocortical development," Journal of Neuroscience, vol. 31, no. 2, pp. 549-564, 2011.

[29] F. Bedogni, R. D. Hodge, G. E. Elsen et al., "Tbrl regulates regional and laminar identity of postmitotic neurons in developing neocortex," Proceedings of the National Academy of Sciences of the United States of America, vol. 107, no. 29, pp. 13129-13134, 2010.

[30] O. Britanova, C. D. J. Romero, A. Cheung et al., "Satb2 is a postmitotic determinant for upper-layer neuron specification in the neocortex," Neuron, vol. 57, no. 3, pp. 378-392, 2008.

[31] E. A. Alcamo, L. Chirivella, M. Dautzenberg et al., "Satb2 regulates callosal projection neuron identity in the developing cerebral cortex," Neuron, vol. 57, no. 3, pp. 364-377, 2008.

[32] L. Zhang, N.-N. Song, J.-Y. Chen, Y. Huang, H. Li, and Y.-Q. Ding, "Satb2 is required for dendritic arborization and soma spacing in mouse cerebral cortex," Cerebral Cortex, vol. 22, no. 7, pp. 1510-1519, 2012.

[33] B. Cubelos, A. Sebastián-Serrano, L. Beccari et al., "Cuxl and Cux2 regulate dendritic branching, spine morphology, and synapses of the upper layer neurons of the cortex," Neuron, vol. 66, no. 4, pp. 523-535, 2010.

[34] R. Benavides-Piccione, F. Hamzei-Sichani, I. Ballesteros-Yáñez, J. Defelipe, and R. Yuste, "Dendritic size of pyramidal neurons differs among mouse cortical regions," Cerebral Cortex, vol. 16, no. 7, pp. 990-1001, 2006.
[35] K. Sumiyama, K. Washio-Watanabe, N. Saitou, T. Hayakawa, and S. Ueda, "Class III POU genes: generation of homopolymeric amino acid repeats under GC pressure in mammals," Journal of Molecular Evolution, vol. 43, no. 3, pp. 170-178, 1996.

[36] R. J. McEvilly, M. O. de Diaz, M. D. Schonemann, F. Hooshmand, and M. G. Rosenfeld, "Transcriptional regulation of cortical neuron migration by POU domain factors," Science, vol. 295, no. 5559, pp. 1528-1532, 2002.

[37] Y. Sugitani, S. Nakai, O. Minowa et al., "Brn-1 and Brn-2 share crucial roles in the production and positioning of mouse neocortical neurons," Genes and Development, vol. 16, no. 14, pp. 1760-1765, 2002.

[38] M. H. Dominguez, A. E. Ayoub, and P. Rakic, "POU-III transcription factors (Brn1, Brn2, and Oct6) influence neurogenesis, molecular identity, and migratory destination of upper-layer cells of the cerebral cortex," Cerebral Cortex, vol. 23, no. 11, pp. 2632-2643, 2013.

[39] V. Tarabykin, A. Stoykova, N. Usman, and P. Gruss, "Cortical upper layer neurons derive from the subventricular zone as indicated by Svetl gene expression," Development, vol. 128, no. 11, pp. 1983-1993, 2001.

[40] P. W. Land and A. P. Monaghan, "Expression of the transcription factor, tailless, is required for formation of superficial cortical layers," Cerebral Cortex, vol. 13, no. 9, pp. 921-931, 2003.

[41] J. Wen, Q. Hu, M. Li et al., "Pax6 directly modulate Sox2 expression in the neural progenitor cells," Neuroreport, vol. 19, no. 4, pp. 413-417, 2008.

[42] C. Alfano, L. Viola, J. I. Heng et al., "COUP-TFI promotes radial migration and proper morphology of callosal projection neurons by repressing Rnd2 expression," Development, vol. 138, no. 21, pp. 4685-4697, 2011.

[43] D. O'Leary and S. Sahara, "Genetic regulation of arealization of the neocortex," Current Opinion in Neurobiology, vol. 18, no. 1, pp. 90-100, 2008.

[44] J. Aubert, M. P. Stavridis, S. Tweedie et al., "Screening for mammalian neural genes via fluorescence-activated cell sorter purification of neural precursors from Soxl-gfp knock-in mice," Proceedings of the National Academy of Sciences of the United States of America, vol. 100, no. 1, pp. 11836-11841, 2003.

[45] C. Zhao, W. Deng, and F. H. Gage, "Mechanisms and functional implications of adult neurogenesis," Cell, vol. 132, no. 4, pp. 645660, 2008.

[46] O. V. B. U. Halbach, "Immunohistological markers for staging neurogenesis in adult hippocampus," Cell and Tissue Research, vol. 329, no. 3, pp. 409-420, 2007.

[47] E. Bazán, F. J. M. Alonso, C. Redondo et al., "In vitro and in vivo characterization of neural stem cells," Histology and Histopathology, vol. 19, no. 4, pp. 1261-1275, 2004.

[48] X. Duan, E. Kang, C. Y. Liu et al., "Development of neural stem cell in the adult brain," Current Opinion in Neurobiology, vol. 18, no. 1, pp. 108-115, 2008.

[49] F. A. Siebzehnrubl, V. Vedam-Mai, H. Azari, B. A. Reynolds, and L. P. Deleyrolle, "Isolation and characterization of adult neural stem cells," Methods in Molecular Biology, vol. 750, pp. 61-77, 2011.

[50] T. E. Anthony, C. Klein, G. Fishell, and N. Heintz, "Radial glia serve as neuronal progenitors in all regions of the central nervous system," Neuron, vol. 41, no. 6, pp. 881-890, 2004.

[51] D. K. Ma, M. A. Bonaguidi, G.-L. Ming, and H. Song, "Adult neural stem cells in the mammalian central nervous system," Cell Research, vol. 19, no. 6, pp. 672-682, 2009. 
[52] G. Kempermann, H. G. Kuhn, and F. H. Gage, "Experienceinduced neurogenesis in the senescent dentate gyrus," The Journal of Neuroscience, vol. 18, no. 9, pp. 3206-3212, 1998.

[53] B. Steiner, S. Zurborg, H. Hörster, K. Fabel, and G. Kempermann, "Differential $24 \mathrm{~h}$ responsiveness of Proxl-expressing precursor cells in adult hippocampal neurogenesis to physical activity, environmental enrichment, and kainic acid-induced seizures," Neuroscience, vol. 154, no. 2, pp. 521-529, 2008.

[54] G. L. Ming and H. Song, "Adult neurogenesis in the mammalian central nervous system," Annual Review of Neuroscience, vol. 28, pp. 223-250, 2005.

[55] V. Filippov, G. Kronenberg, T. Pivneva et al., "Subpopulation of nestin-expressing progenitor cells in the adult murine hippocampus shows electrophysiological and morphological characteristics of astrocytes," Molecular and Cellular Neuroscience, vol. 23, no. 3, pp. 373-382, 2003.

[56] S. Fukuda, F. Kato, Y. Tozuka, M. Yamaguchi, Y. Miyamoto, and T. Hisatsune, "Two distinct subpopulations of nestin-positive cells in adult mouse dentate gyrus," The Journal of Neuroscience, vol. 23, no. 28, pp. 9357-9366, 2003.

[57] J. M. Parent, T. W. Yu, R. T. Leibowitz, D. H. Geschwind, R. S. Sloviter, and D. H. Lowenstein, "Dentate granule cell neurogenesis is increased by seizures and contributes to aberrant network reorganization in the adult rat hippocampus," The Journal of Neuroscience, vol. 17, no. 10, pp. 3727-3738, 1997.

[58] E. Gould, H. A. Cameron, D. C. Daniels, C. S. Woolley, and B. S. McEwen, "Adrenal hormones suppress cell division in the adult rat dentate gyrus," The Journal of Neuroscience, vol. 12, no. 9, pp. 3642-3650, 1992.

[59] G. Kronenberg, K. Reuter, B. Steiner et al., "Subpopulations of proliferating cells of the adult hippocampus respond differently to physiologic neurogenic stimuli," Journal of Comparative Neurology, vol. 467, no. 4, pp. 455-463, 2003.

[60] J. P. Brown, S. Couillard-Després, C. M. Cooper-Kuhn, J. Winkler, L. Aigner, and H. G. Kuhn, "Transient expression of doublecortin during adult neurogenesis," Journal of Comparative Neurology, vol. 467, no. 1, pp. 1-10, 2003.

[61] M. D. Brandt, S. Jessberger, B. Steiner et al., "Transient calretinin expression defines early postmitotic step of neuronal differentiation in adult hippocampal neurogenesis of mice," Molecular and Cellular Neuroscience, vol. 24, no. 3, pp. 603-613, 2003.

[62] Z. Li, T. Kato, K. Kawagishi, N. Fukushima, K. Yokouchi, and T. Moriizumi, "Cell dynamics of calretinin-immunoreactive neurons in the rostral migratory stream after ibotenate-induced lesions in the forebrain," Neuroscience Research, vol. 42, no. 2, pp. 123-132, 2002.

[63] S. Jessberger and G. Kempermann, "Adult-born hippocampal neurons mature into activity-dependent responsiveness," European Journal of Neuroscience, vol. 18, no. 10, pp. 2707-2712, 2003.

[64] A. Zacchetti, E. Van Garderen, E. Teske, H. Nederbragt, J. H. Dierendonck, and G. R. Rutteman, "Validation of the use of proliferation markers in canine neoplastic and non-neoplastic tissues: comparison of KI-67 and proliferating cell nuclear antigen (PCNA) expression versus in vivo bromodeoxyuridine labelling by immunohistochemistry," APMIS, vol. 111, no. 3, pp. 430-438, 2003.

[65] T. L. Limke, J. Cai, T. Miura, M. S. Rao, and M. P. Mattson, "Distinguishing features of progenitor cells in the late embryonic and adult hippocampus," Developmental Neuroscience, vol. 25, no. 2-4, pp. 257-272, 2003.
[66] S. Jinno, "Topographic differences in adult neurogenesis in the mouse hippocampus: a stereology-based study using endogenous markers," Hippocampus, vol. 21, no. 5, pp. 467-480, 2011.

[67] P. Taupin, "BrdU immunohistochemistry for studying adult neurogenesis: paradigms, pitfalls, limitations, and validation," Brain Research Reviews, vol. 53, no. 1, pp. 198-214, 2007.

[68] O. Von Bohlen Und Halbach, "Immunohistological markers for proliferative events, gliogenesis, and neurogenesis within the adult hippocampus," Cell and Tissue Research, vol. 345, no. 1, pp. $1-19,2011$.

[69] H. G. Kuhn, H. Dickinson-Anson, and F. H. Gage, "Neurogenesis in the dentate gyrus of the adult rat: age-related decrease of neuronal progenitor proliferation," The Journal of Neuroscience, vol. 16, no. 6, pp. 2027-2033, 1996.

[70] G. Kempermann, H. G. Kuhn, and F. H. Gage, "More hippocampal neurons in adult mice living in an enriched environment," Nature, vol. 386, no. 6624, pp. 493-495, 1997.

[71] G. Kempermann, D. Gast, G. Kronenberg, M. Yamaguchi, and F. H. Gage, "Early determination and long-term persistence of adult-generated new neurons in the hippocampus of mice," Development, vol. 130, no. 2, pp. 391-399, 2003.

[72] P. J. Lucassen, M. W. Stumpel, Q. Wang, and E. Aronica, "Decreased numbers of progenitor cells but no response to antidepressant drugs in the hippocampus of elderly depressed patients," Neuropharmacology, vol. 58, no. 6, pp. 940-949, 2010.

[73] A. Hanna-Morris, S. Badvie, P. Cohen, T. McCullough, H. J. N. Andreyev, and T. G. Allen-Marsh, "Minichromosome maintenance protein 2 (MCM2) is a stronger discriminator of increased proliferation in mucosa adjacent to colorectal cancer than Ki-67," Journal of Clinical Pathology, vol. 62, no. 4, pp. 325$330,2009$.

[74] J. Szymas and F. Tokarz, "Determination of the glial fibrillary acidic protein in human cerebrospinal fluid and in cyst fluid of brain tumors," Acta Neurochirurgica, vol. 83, no. 3-4, pp. 144150, 1986.

[75] F. Doetsch, J. M. García-Verdugo, and A. Alvarez-Buylla, "Cellular composition and three-dimensional organization of the subventricular germinal zone in the adult mammalian brain," Journal of Neuroscience, vol. 17, no. 13, pp. 5046-5061, 1997.

[76] A. R. Kriegstein and M. Götz, "Radial glia diversity: a matter of cell fate," GLIA, vol. 43, no. 1, pp. 37-43, 2003.

[77] J. H. Veerkamp and A. W. Zimmerman, "Fatty acid-binding proteins of nervous tissue," Journal of Molecular Neuroscience, vol. 16, no. 2-3, pp. 133-142, 2001.

[78] M. Sibbe, E. Förster, O. Basak, V. Taylor, and M. Frotscher, "Reelin and Notch1 cooperate in the development of the dentate gyrus," The Journal of Neuroscience, vol. 29, no. 26, pp. 8578$8585,2009$.

[79] L. Pinto and M. Götz, "Radial glial cell heterogeneity-the source of diverse progeny in the CNS," Progress in Neurobiology, vol. 83, no. 1, pp. 2-23, 2007.

[80] B. Steiner, F. Klempin, L. Wang, M. Kott, H. Kettenmann, and G. Kempermann, "Type-2 cells as link between glial and neuronal lineage in adult hippocampal neurogenesis," GLIA, vol. 54, no. 8, pp. 805-814, 2006.

[81] B. Brunne, S. Zhao, A. Derouiche et al., "Origin, maturation, and astroglial transformation of secondary radial glial cells in the developing dentate gyrus," Glia, vol. 58, no. 13, pp. 1553-1569, 2010.

[82] M. Kipp, S. Gingele, F. Pott et al., "BLBP-expression in astrocytes during experimental demyelination and in human multiple 
sclerosis lesions," Brain, Behavior, and Immunity, vol. 25, no. 8, pp. 1554-1568, 2011.

[83] A. A. Avilion, S. K. Nicolis, L. H. Pevny, L. Perez, N. Vivian, and R. Lovell-Badge, "Multipotent cell lineages in early mouse development depend on SOX2 function," Genes and Development, vol. 17, no. 1, pp. 126-140, 2003.

[84] A. L. M. Ferri, M. Cavallaro, D. Braida et al., "Sox2 deficiency causes neurodegeneration and impaired neurogenesis in the adult mouse brain," Development, vol. 131, no. 15, pp. 3805-3819, 2004.

[85] A. Rizzino, "Sox2 and Oct-3/4: a versatile pair of master regulators that orchestrate the self-renewal and pluripotency of embryonic stem cells," Wiley Interdisciplinary Reviews: Systems Biology and Medicine, vol. 1, no. 2, pp. 228-236, 2009.

[86] H. Suh, A. Consiglio, J. Ray, T. Sawai, K. A. D’Amour, and F. Gage, "In vivo fate analysis reveals the multipotent and self-renewal capacities of $\mathrm{Sox}^{2+}$ neural stem cells in the adult hippocampus," Cell Stem Cell, vol. 1, no. 5, pp. 515-528, 2007.

[87] J. Cai, A. Cheng, Y. Luo et al., "Membrane properties of rat embryonic multipotent neural stem cells," Journal of Neurochemistry, vol. 88, no. 1, pp. 212-226, 2003.

[88] R. Marmur, P. C. Mabie, S. Gokhan, Q. Song, J. A. Kessler, and M. F. Mehler, "Isolation and developmental characterization of cerebral cortical multipotent progenitors," Developmental Biology, vol. 204, no. 2, pp. 577-591, 1998.

[89] T. Seki, "Expression patterns of immature neuronal markers PSA-NCAM, CRMP-4 and NeuroD in the hippocampus of young adult and aged rodents," Journal of Neuroscience Research, vol. 70, no. 3, pp. 327-334, 2002.

[90] T. Seki, "Hippocampal adult neurogenesis occurs in a microenvironment provided by PSA-NCAM-expressing immature neurons," Journal of Neuroscience Research, vol. 69, no. 6, pp. 772783, 2002.

[91] F. Doetsch, I. Caillé, D. A. Lim, J. M. Garcia-Verdugo, and A. Alvarez-Buylla, "Subventricular zone astrocytes are neural stem cells in the adult mammalian brain," Cell, vol. 97, no. 6, pp. 703716, 1999.

[92] T. Kawai, N. Takagi, K. Miyake-Takagi, N. Okuyama, N. Mochizuki, and S. Takeo, "Characterization of BrdU-Positive Neurons Induced by Transient Global Ischemia in Adult Hippocampus," Journal of Cerebral Blood Flow and Metabolism, vol. 24, no. 5, pp. 548-555, 2004.

[93] R. F. Hevner, R. D. Hodge, R. A. M. Daza, and C. Englund, "Transcription factors in glutamatergic neurogenesis: conserved programs in neocortex, cerebellum, and adult hippocampus," Neuroscience Research, vol. 55, no. 3, pp. 223-233, 2006.

[94] M. Liu, S. J. Pleasure, A. E. Collins et al., "Loss of BETA2/NeuroD leads to malformation of the dentate gyrus and epilepsy," Proceedings of the National Academy of Sciences of the United States of America, vol. 97, no. 2, pp. 865-870, 2000.

[95] J. Nacher, E. Varea, J. M. Blasco-Ibañez et al., "Expression of the transcription factor Pax6 in the adult rat dentate gyrus," Journal of Neuroscience Research, vol. 81, no. 6, pp. 753-761, 2005.

[96] N. Osumi, H. Shinohara, K. Numayama-Tsuruta, and M. Maekawa, "Concise review: Pax6 transcription factor contributes to both embryonic and adult neurogenesis as a multifunctional regulator," Stem Cells, vol. 26, no. 7, pp. 1663-1672, 2008.

[97] J. Ninkovic, L. Pinto, S. Petricca et al., “The transcription factor Pax6 regulates survival of dopaminergic olfactory bulb neurons via crystallin $\alpha$ A," Neuron, vol. 68, no. 4, pp. 682-694, 2010.
[98] M. S. Brill, J. Ninkovic, E. Winpenny et al., "Adult generation of glutamatergic olfactory bulb interneurons," Nature Neuroscience, vol. 12, no. 12, pp. 1524-1533, 2009.

[99] C. Englund, A. Fink, C. Lau et al., "Pax6, Tbr2, and Tbr1 are expressed sequentially by radial glia, intermediate progenitor cells, and postmitotic neurons in developing neocortex," Journal of Neuroscience, vol. 25, no. 1, pp. 247-251, 2005.

[100] M. Maekawa, N. Takashima, Y. Arai et al., "Pax6 is required for production and maintenance of progenitor cells in postnatal hippocampal neurogenesis," Genes to Cells, vol. 10, no. 10, pp. 1001-1014, 2005.

[101] J. C. Quinn, M. Molinek, B. S. Martynoga et al., "Pax6 controls cerebral cortical cell number by regulating exit from the cell cycle and specifies cortical cell identity by a cell autonomous mechanism," Developmental Biology, vol. 302, no. 1, pp. 50-65, 2007.

[102] Z. Molnár and A. F. P. Cheung, "Towards the classification of subpopulations of layer V pyramidal projection neurons," Neuroscience Research, vol. 55, no. 2, pp. 105-115, 2006.

[103] J. Ninkovic, T. Mori, and M. Götz, "Distinct modes of neuron addition in adult mouse neurogenesis," Journal of Neuroscience, vol. 27, no. 40, pp. 10906-10911, 2007.

[104] T. C. Tuoc and A. Stoykova, "Trim11 modulates the function of neurogenic transcription factor Pax6 through ubiquitinproteosome system," Genes and Development, vol. 22, no. 14, pp. 1972-1986, 2008.

[105] D. A. Salih and A. Brunet, "FoxO transcription factors in the maintenance of cellular homeostasis during aging," Current Opinion in Cell Biology, vol. 20, no. 2, pp. 126-136, 2008.

[106] V. M. Renault, V. A. Rafalski, A. A. Morgan et al., "FoxO3 regulates neural stem cell homeostasis," Cell Stem Cell, vol. 5, no. 5, pp. 527-539, 2009.

[107] C. Skurk, H. Maatz, H.-S. Kim et al., “The Akt-regulated forkhead transcription factor FOXO3a controls endothelial cell viability through modulation of the caspase- 8 inhibitor FLIP," Journal of Biological Chemistry, vol. 279, no. 2, pp. 1513-1525, 2004.

[108] S. D. Gopinath, A. E. Webb, A. Brunet, and T. A. Rando, "FOXO3 promotes quiescence in adult muscle stem cells during the process of self-renewal," Stem Cell Reports, vol. 2, no. 4, pp. 414-426, 2014.

[109] U. Lendahl, L. B. Zimmerman, and R. D. G. McKay, "CNS stem cells express a new class of intermediate filament protein," Cell, vol. 60, no. 4, pp. 585-595, 1990.

[110] A. V. Gilyarov, "Nestin in central nervous system cells," Neuroscience and Behavioral Physiology, vol. 38, no. 2, pp. 165-169, 2008.

[111] D. Park, A. P. Xiang, F. F. Mao et al., "Nestin is required for the proper self-renewal of neural stem cells," Stem Cells, vol. 28, no. 12, pp. 2162-2171, 2010.

[112] J. Namiki, S. Suzuki, T. Masuda, Y. Ishihama, and H. Okano, "Nestin protein is phosphorylated in adult neural stem/progenitor cells and not endothelial progenitor cells," Stem Cells International, vol. 2012, Article ID 430138, 5 pages, 2012.

[113] C. Wiese, A. Rolletschek, G. Kania et al., "Nestin expressiona property of multi-lineage progenitor cells?" Cellular and Molecular Life Sciences, vol. 61, no. 19-20, pp. 2510-2522, 2004.

[114] H.-K. Liu, T. Belz, D. Bock et al., "The nuclear receptor tailless is required for neurogenesis in the adult subventricular zone," Genes and Development, vol. 22, no. 18, pp. 2473-2478, 2008. 
[115] S. Li, G. Sun, K. Murai, P. Ye, and Y. Shi, "Characterization of TLX expression in neural stem cells and progenitor cells in adult brains," PLoS ONE, vol. 7, no. 8, Article ID e43324, 2012.

[116] Y. Shi, D. C. Lie, P. Taupin et al., "Expression and function of orphan nuclear receptor TLX in adult neural stem cells," Nature, vol. 427 , no. 6969 , pp. 78-83, 2004.

[117] C.-L. Zhang, Y. Zou, W. He, F. H. Gage, and R. M. Evans, "A role for adult TLX-positive neural stem cells in learning and behaviour," Nature, vol. 451, no. 7181, pp. 1004-1007, 2008.

[118] J. E. Lee, "Basic helix-loop-helix genes in neural development," Current Opinion in Neurobiology, vol. 7, no. 1, pp. 13-20, 1997.

[119] G. Stump, A. Durrer, A.-L. Klein, S. Lütolf, U. Suter, and V. Taylor, "Notch1 and its ligands Delta-like and Jagged are expressed and active in distinct cell populations in the postnatal mouse brain," Mechanisms of Development, vol. 114, no. 1-2, pp. 153-159, 2002.

[120] S. Lugert, O. Basak, P. Knuckles et al., "Quiescent and active hippocampal neural stem cells with distinct morphologies respond selectively to physiological and pathological stimuli and aging," Cell Stem Cell, vol. 6, no. 5, pp. 445-456, 2010.

[121] N. Bertrand, D. S. Castro, and F. Guillemot, "Proneural genes and the specification of neural cell types," Nature Reviews Neuroscience, vol. 3, no. 7, pp. 517-530, 2002.

[122] E. J. Kim, J. L. Ables, L. K. Dickel, A. J. Eisch, and J. E. Johnson, "Ascll (Mash1) defines cells with long-term neurogenic potential in subgranular and subventricular zones in adult mouse brain," PLoS ONE, vol. 6, no. 3, Article ID e18472, 2011.

[123] J. A. Chong, J. Tapia-Ramírez, S. Kim et al., "REST: a mammalian silencer protein that restricts sodium channel gene expression to neurons," Cell, vol. 80, no. 6, pp. 949-957, 1995.

[124] L. Sharling, A. Roopra, I. C. Wood et al., "Transcriptional repression by neuron-restrictive silencer factor is mediated via the Sin3-histone deacetylase complex," Molecular \& Cellular Biology, vol. 20, no. 6, pp. 2147-2157, 2000.

[125] N. Ballas, E. Battaglioli, F. Atouf et al., "Regulation of neuronal traits by a novel transcriptional complex," Neuron, vol. 31, no. 3, pp. 353-365, 2001.

[126] Y.-M. Sun, D. J. Greenway, R. Johnson et al., "Distinct profiles of REST interactions with its target genes at different stages of neuronal development," Molecular Biology of the Cell, vol. 16, no. 12, pp. 5630-5638, 2005.

[127] Z. Gao, K. Ure, P. Ding et al., "The master negative regulator REST/NRSF controls adult neurogenesis by restraining the neurogenic program in quiescent stem cells," Journal of Neuroscience, vol. 31, no. 26, pp. 9772-9786, 2011.

[128] A. G. Dayer, K. M. Cleaver, T. Abouantoun, and H. A. Cameron, "New GABAergic interneurons in the adult neocortex and striatum are generated from different precursors," The Journal of Cell Biology, vol. 168, no. 3, pp. 415-427, 2005.

[129] S. Couillard-Despres, B. Winner, C. Karl et al., "Targeted transgene expression in neuronal precursors: watching young neurons in the old brain," European Journal of Neuroscience, vol. 24, no. 6, pp. 1535-1545, 2006.

[130] B. Seri, J. M. García-Verdugo, B. S. McEwen, and A. AlvarezBuylla, "Astrocytes give rise to new neurons in the adult mammalian hippocampus," Journal of Neuroscience, vol. 21, no. 18, pp. 7153-7160, 2001.

[131] D. Ehninger and G. Kempermann, "Neurogenesis in the adult hippocampus," Cell and Tissue Research, vol. 331, no. 1, pp. 243$250,2008$.
[132] E. Raponi, F. Agenes, C. Delphin et al., "S100B expression defines a state in which GFAP-expressing cells lose their neural stem cell potential and acquire a more mature developmental stage," Glia, vol. 55, no. 2, pp. 165-177, 2007.

[133] B. Seri, J. M. García-Verdugo, L. Collado-Morente, B. S. McEwen, and A. Alvarez-Buylla, "Cell types, lineage, and architecture of the germinal zone in the adult dentate gyrus," Journal of Comparative Neurology, vol. 478, no. 4, pp. 359-378, 2004.

[134] P. Kugler and V. Schleyer, "Developmental expression of glutamate transporters and glutamate dehydrogenase in astrocytes of the postnatal rat hippocampus," Hippocampus, vol. 14, no. 8, pp. 975-985, 2004.

[135] T. Namba, H. Mochizuki, M. Onodera, Y. Mizuno, H. Namiki, and T. Seki, "The fate of neural progenitor cells expressing astrocytic and radial glial markers in the postnatal rat dentate gyrus," European Journal of Neuroscience, vol. 22, no. 8, pp. 1928-1941, 2005.

[136] G. Barry, M. Piper, C. Lindwall et al., "Specific glial populations regulate hippocampal morphogenesis," Journal of Neuroscience, vol. 28, no. 47, pp. 12328-12340, 2008.

[137] D. N. Plachez and M. Récasens, "Transient expression of the glial glutamate transporters GLAST and GLT in hippocampal neurons in primary culture," Journal of Neuroscience Research, vol. 59, no. 5, pp. 587-593, 2000.

[138] A. Lee and D. V. Pow, "Astrocytes: glutamate transport and alternate splicing of transporters," International Journal of Biochemistry and Cell Biology, vol. 42, no. 12, pp. 1901-1906, 2010.

[139] N. Kimura, K. Nakashima, M. Ueno, H. Kiyama, and T. Taga, "A novel mammalian T-box-containing gene, Tbr2, expressed in mouse developing brain," Developmental Brain Research, vol. 115, no. 2, pp. 183-193, 1999.

[140] R. D. Hodge, T. D. Kowalczyk, S. A. Wolf et al., "Intermediate progenitors in adult hippocampal neurogenesis: Tbr2 expression and coordinate regulation of neuronal output," Journal of Neuroscience, vol. 28, no. 14, pp. 3707-3717, 2008.

[141] P. Ambrogini, D. Lattanzi, S. Ciuffoli et al., "Morpho-functional characterization of neuronal cells at different stages of maturation in granule cell layer of adult rat dentate gyrus," Brain Research, vol. 1017, no. 1-2, pp. 21-31, 2004.

[142] H. K. C. Yang, N. L. Sundholm-Peters, G. E. Goings, A. S. Walker, K. Hyland, and F. G. Szele, "Distribution of doublecortin expressing cells near the lateral ventricles in the adult mouse brain," Journal of Neuroscience Research, vol. 76, no. 3, pp. 282-295, 2004.

[143] A. Lavado, O. V. Lagutin, L. M. L. Chow, S. J. Baker, and G. Oliver, "Proxl is required for granule cell maturation and intermediate progenitor maintenance during brain neurogenesis," PLoS Biology, vol. 8, no. 8, pp. 43-44, 2010.

[144] I. Navaero-Quiroga, M. Fernandez-Valdes, S. L. Lin, and J. R. Naegele, "Postnatal cellular contributions of the hippocampus subventricular zone to the dentate gyrus, corpus callosum, fimbria, and cerebral cortex," Journal of Comparative Neurology, vol. 497, no. 5, pp. 833-845, 2006.

[145] H. Kasama-Yoshida, Y. Tohyama, T. Kurihara, M. Sakuma, H. Kojima, and Y. Tamai, "A comparative study of 2,3'-cyclicnucleotide 3'-phosphodiesterase in vertebrates: cDNA cloning and amino acid sequences for chicken and bullfrog enzymes," Journal of Neurochemistry, vol. 69, no. 4, pp. 1335-1342, 1997.

[146] M. S. Davidoff, R. Middendorff, E. Köfüncü, D. Müller, D. Ježek, and A.-F. Holstein, "Leydig cells of the human testis 
possess astrocyte and oligodendrocyte marker molecules," Acta Histochemica, vol. 104, no. 1, pp. 39-49, 2002.

[147] C. K. Tong and A. Alvarez-Buylla, "SnapShot: adult Neurogenesis in the V-SVZ," Neuron, vol. 81, no. 1, pp. 220-220.el, 2014.

[148] X. Liu, A. J. Bolteus, D. M. Balkin, O. Henschel, and A. Bordey, "GFAP-expressing cells in the postnatal subventricular zone display a unique glial phenotype intermediate between radial glia and astrocytes," Glia, vol. 54, no. 5, pp. 394-410, 2006.

[149] T. Nomura, C. Göritz, T. Catchpole, M. Henkemeyer, and J. Frisén, "EphB signaling controls lineage plasticity of adult neural stem cell niche cells," Cell Stem Cell, vol. 7, no. 6, pp. 730743, 2010.

[150] S. Bovetti, P. Bovolin, I. Perroteau, and A. C. Puche, "Subventricular zone-derived neuroblast migration to the olfactory bulb is modulated by matrix remodelling," European Journal of Neuroscience, vol. 25, no. 7, pp. 2021-2033, 2007.

[151] C. M. Parras, R. Galli, O. Britz et al., "Mash1 specifies neurons and oligodendrocytes in the postnatal brain," The EMBO Journal, vol. 23, no. 22, pp. 4495-4505, 2004.

[152] B. V. Jacquet, R. Salinas-Mondragon, H. Liang et al., "FoxJ1dependent gene expression is required for differentiation of radial glia into ependymal cells and a subset of astrocytes in the postnatal brain," Development, vol. 136, no. 23, pp. 4021-4031, 2009.

[153] M. Tavazoie, L. Van der Veken, V. Silva-Vargas et al., "A specialized vascular niche for adult neural stem cells," Cell Stem Cell, vol. 3, no. 3, pp. 279-288, 2008.

[154] S. Pennartz, R. Belvindrah, S. Tomiuk et al., "Purification of neuronal precursors from the adult mouse brain: comprehensive gene expression analysis provides new insights into the control of cell migration, differentiation, and homeostasis," Molecular and Cellular Neuroscience, vol. 25, no. 4, pp. 692-706, 2004. 

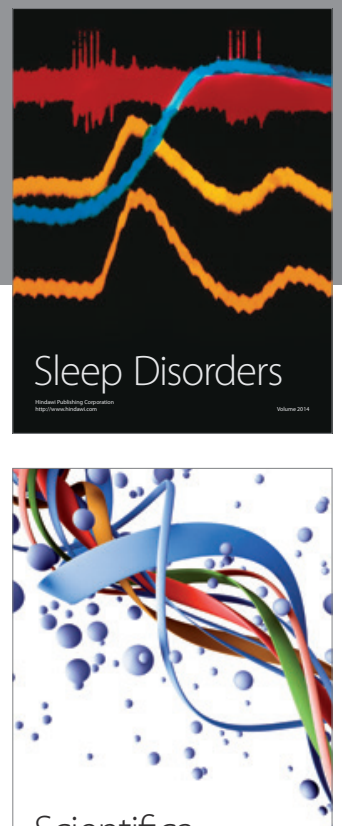

Scientifica
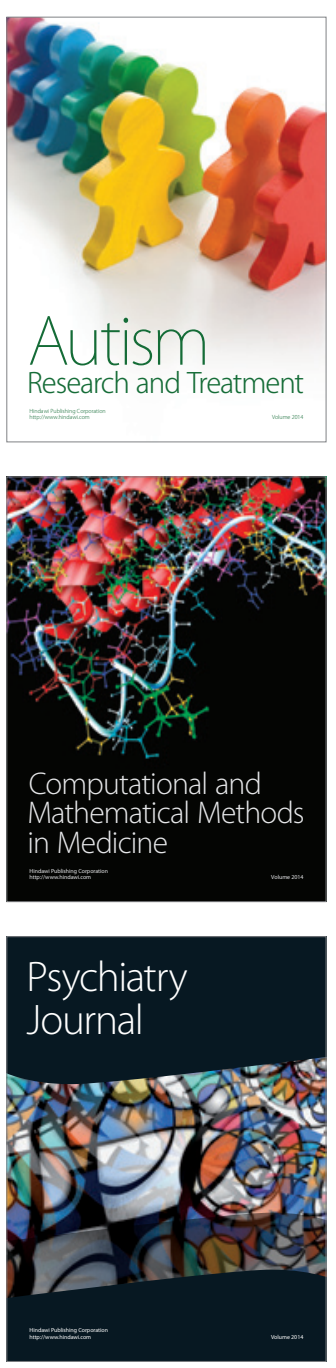
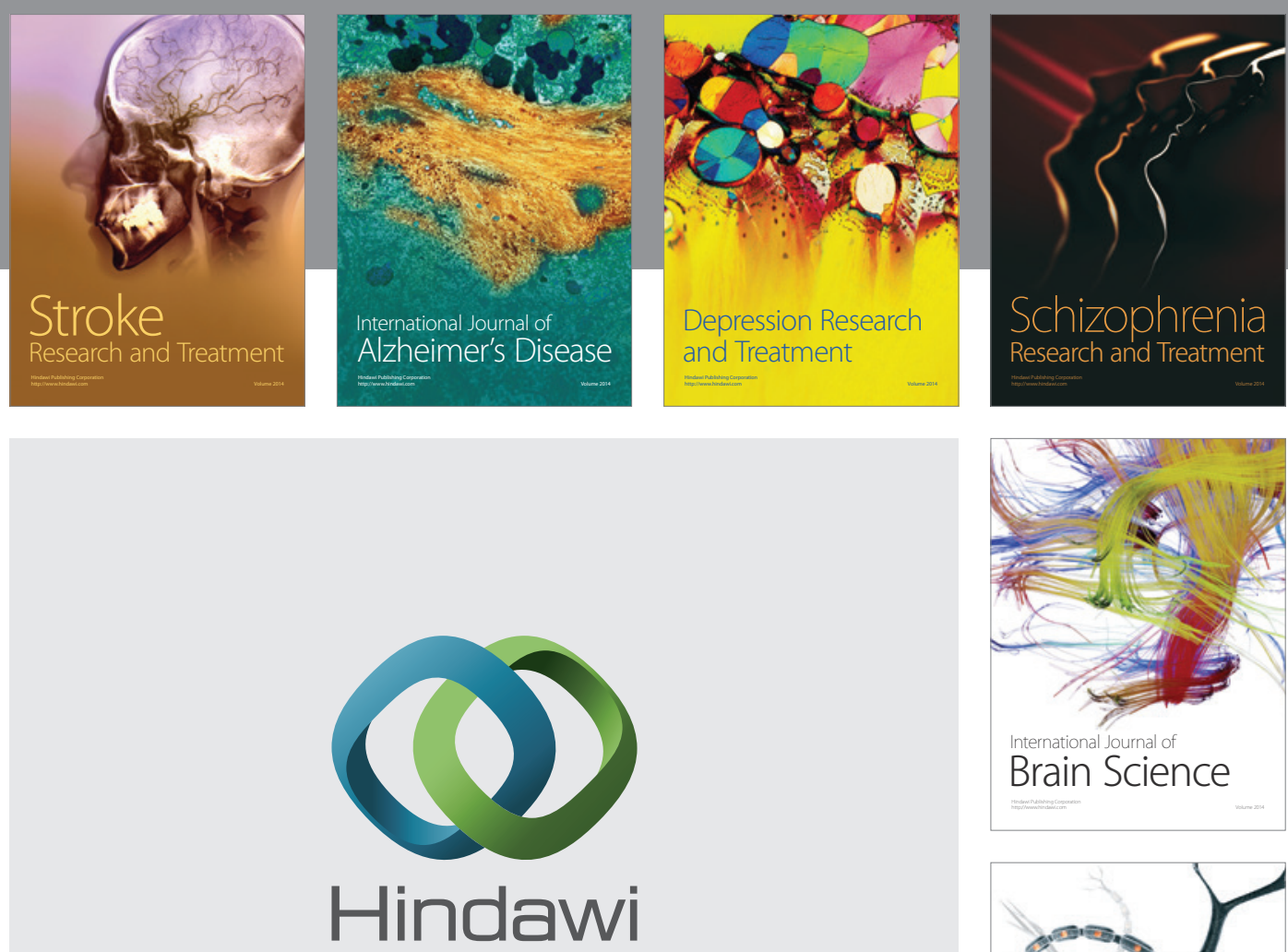

Submit your manuscripts at

http://www.hindawi.com
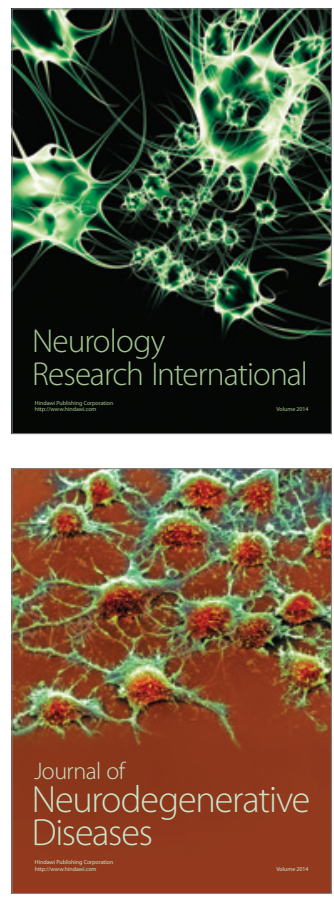

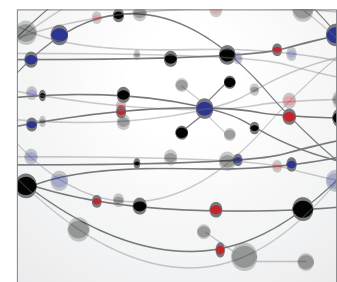

The Scientific World Journal
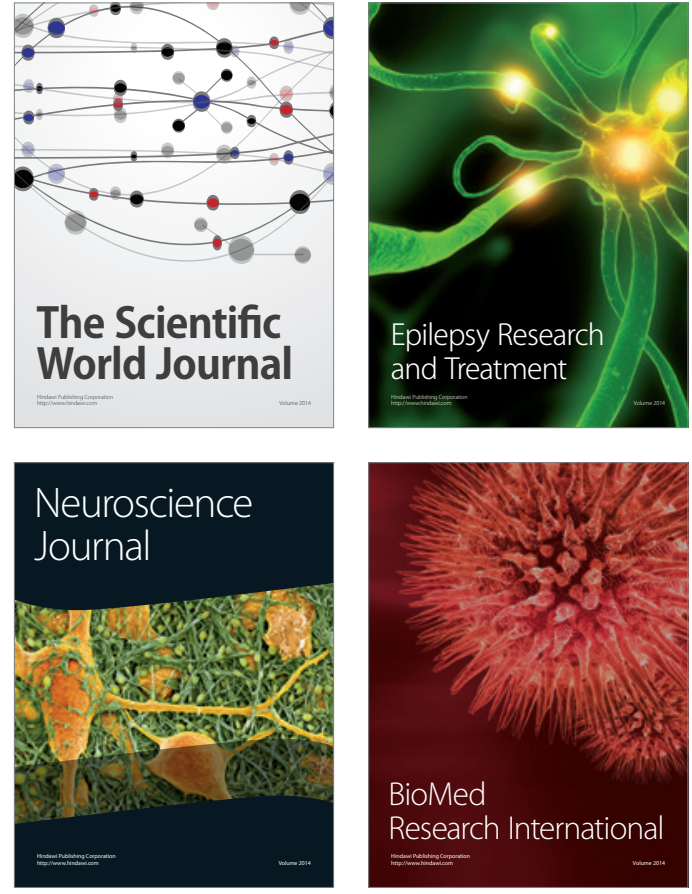

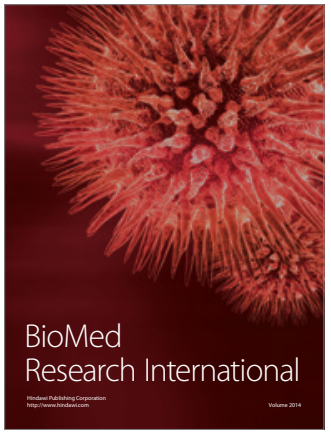

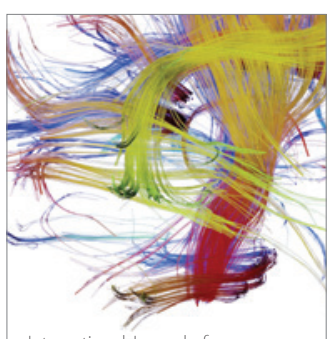

Brain Science

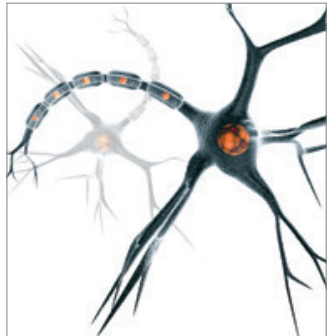

Neural Plasticity
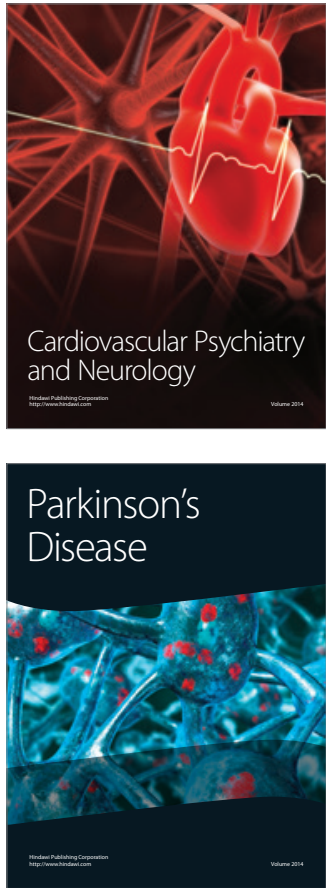